\title{
A Magnitude 7.1 Earthquake in the Tacoma Fault Zone- A Plausible Scenario for the Southern Puget Sound Region, Washington
}

The U.S. Geological Survey
and cooperating scientists
have recently assessed the
effects of a magnitude 7.1
earthquake on the Tacoma
Fault Zone in Pierce County,
Washington. A quake of
comparable magnitude struck
the southern Puget Sound
region about 1,100 years ago,
and similar earthquakes are
almost certain to occur in the
future. The region is now home
to hundreds of thousands of
people, who would be at risk
from the shaking, liquefaction,
landsliding, and tsunamis
caused by such an earthquake.
The modeled effects of this
scenario earthquake will
help emergency planners and
residents of the region prepare
for future quakes.

Scientists with the U.S. Geological Survey (USGS) and cooperating organizations have recently simulated the shaking from a magnitude 7.1 earthquake in the Tacoma Fault Zone, in the southern Puget Sound region, Washington. This "scenario" models the groundmotion amplitudes for a hypothetical rupture along a fault plane that extends from the surface to 9 miles ( $15 \mathrm{~km}$ ) deep and is 35 miles $(56 \mathrm{~km})$ in length, from Belfair through Vashon Island to near the city of Federal Way. These ground motions are derived using computer models with inputs from geological and geophysical observations specific to the region and the fault zone.

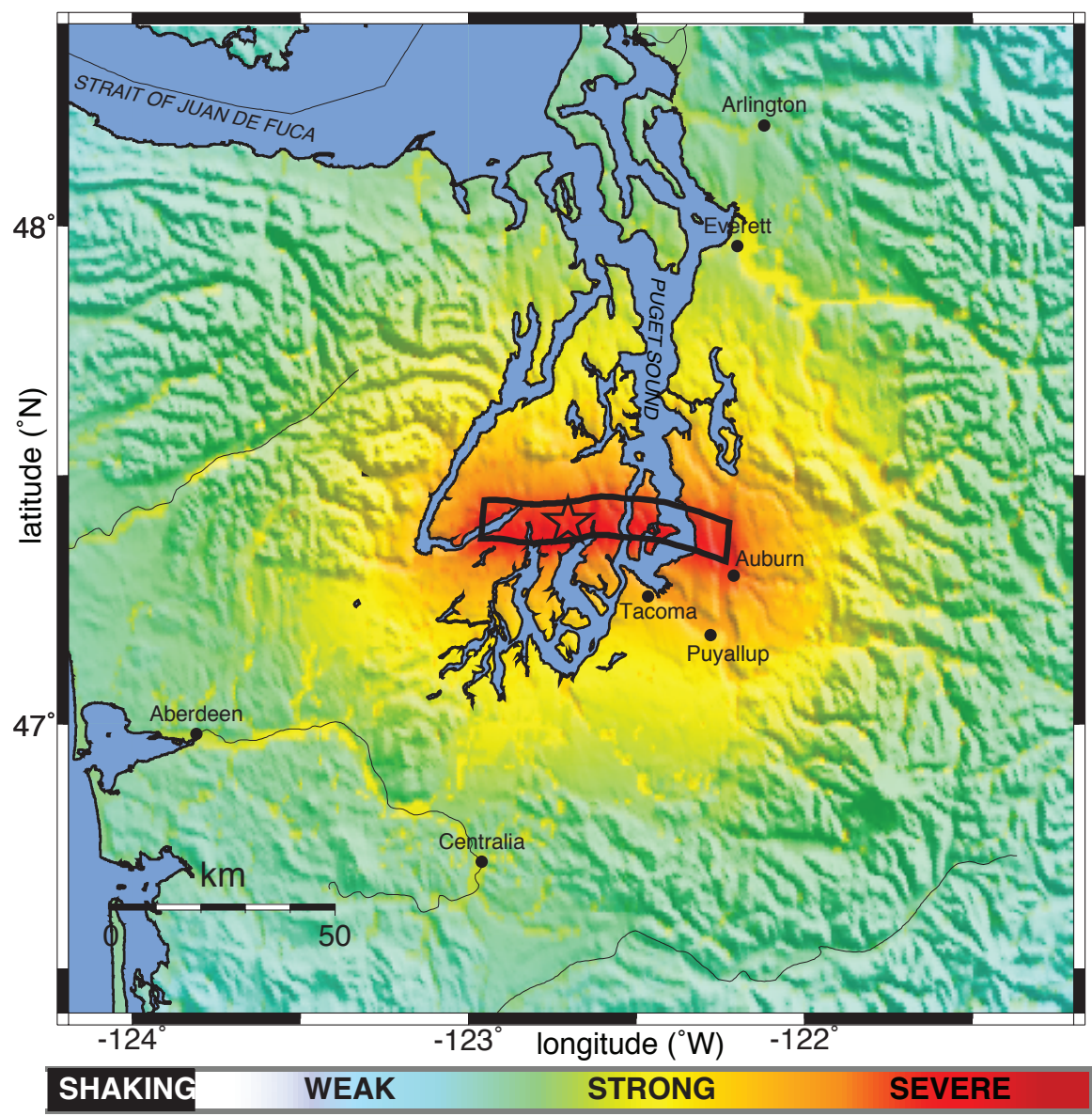

This senario "ShakeMap" shows hypothetical horizontal ground motions for a magnitude 7.1 earthquake in the Tacoma Fault Zone. The strongest shaking (warm colors) occurs in a band close to the fault (black polygon) and in low-lying areas filled with sediments that amplify ground motions, such as the Tacoma Basin area located south of the fault zone. ShakeMaps show "instrumental" intensities, which are measures of the severity of shaking and its impacts. For real earthquakes, intensities are derived automatically by computers from the amplitudes of seismic waves recorded at monitoring stations located throughout the region affected by an earthquake. Although this ShakeMap is for a hypothetical earthquake, scientists have found evidence that a quake of similar magnitude struck the southern Puget Sound region about 1,100 years ago.

\section{The Tacoma Fault Zone}

Local and regional experts have identified several strands of the Tacoma Fault Zone in the southern Puget Sound region, although the eastern extent of the zone remains uncertain. Changes in elevations of coastal marshes surrounding the Tacoma Fault Zone document a large, approximately magnitude 7 earthquake that occurred about 1,100 years ago. Studies are underway to identify evidence of earlier quakes and to more accurately describe the fault system. The ground 
shaking and fault offset of several yards (meters) during a future major earthquake on the Tacoma Fault Zone would cause landsliding, liquefaction, and possibly a tsunami in Puget Sound. These effects are summarized below.

\section{Ground Motions}

Most earthquake hazards result from the shaking, or ground motions, caused by seismic waves that radiate out from a fault as it ruptures. Several factors affect the resulting pattern of shaking. Seismic waves transmit the energy released by the earthquake, and bigger quakes generate larger and longer lasting waves. The rock and sediment layers that the waves travel through affect their strength and duration. The pattern of shaking is affected by the dimensions and orientation of a fault and by the characteristics of the rapid slippage along it that occurs during an earthquake. The proximity of the rupture to the ground surface also significantly affects the strength and pattern of shaking. Deep quakes, like the magnitude 6.8 Nisqually, Washington, earthquake in 2001 and others like it in 1965 and 1949, tend to be much less damaging than shallow ones of comparable magnitude, like the surfacebreaking scenario earthquake modeled in the Tacoma Fault Zone. This difference is primarily due to the fact that in deeper quakes the seismic waves have lost more energy by the time they reach the surface. Unlike deep earthquakes that usually have few to no aftershocks, a magnitude 7.1 earthquake like the one in this scenario would likely have many aftershocks, a few of which could be large enough to be damaging.

\section{Other Earthquake Effects}

Tsunamis - Scientists anticipate that a magnitude 7.1 earthquake in the Tacoma Fault Zone that ruptures a fault reaching the ground surface could offset the floor of Puget Sound and generate a tsunami. Delta failures and landslides caused by the shaking will also likely create or amplify tsunamis. Geological and

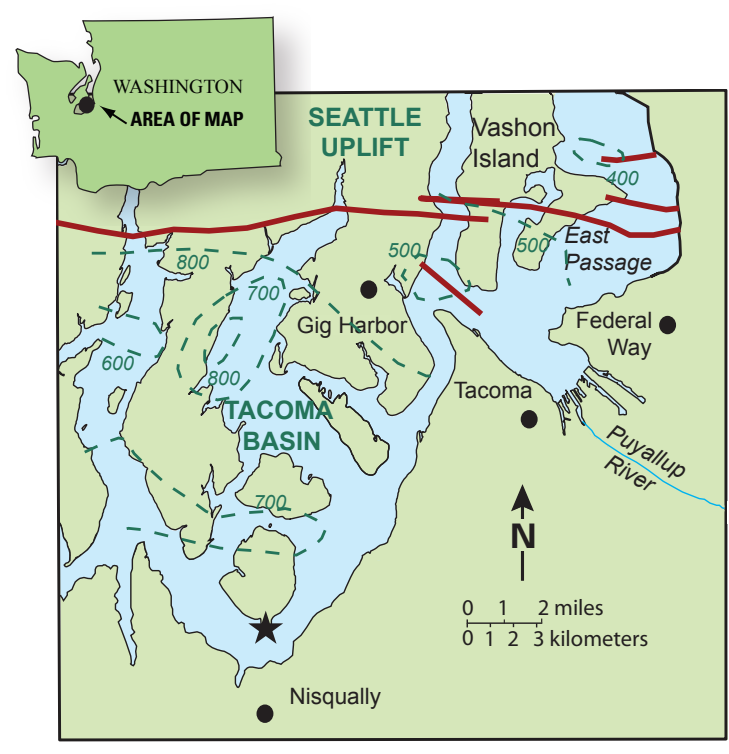

Map showing the location of several strands of the Tacoma Fault Zone (red lines) near Tacoma, Washington. The subsurface structure of the Tacoma Basin is shown by the depth of the unconsolidated sediments (green contours in meters; $1 \mathrm{~m}$ is about 3.28 $\mathrm{ft})$; these sediments may amplify ground shaking during an earthquake. Star shows the epicenter of the 2001 Nisqually earthquake.

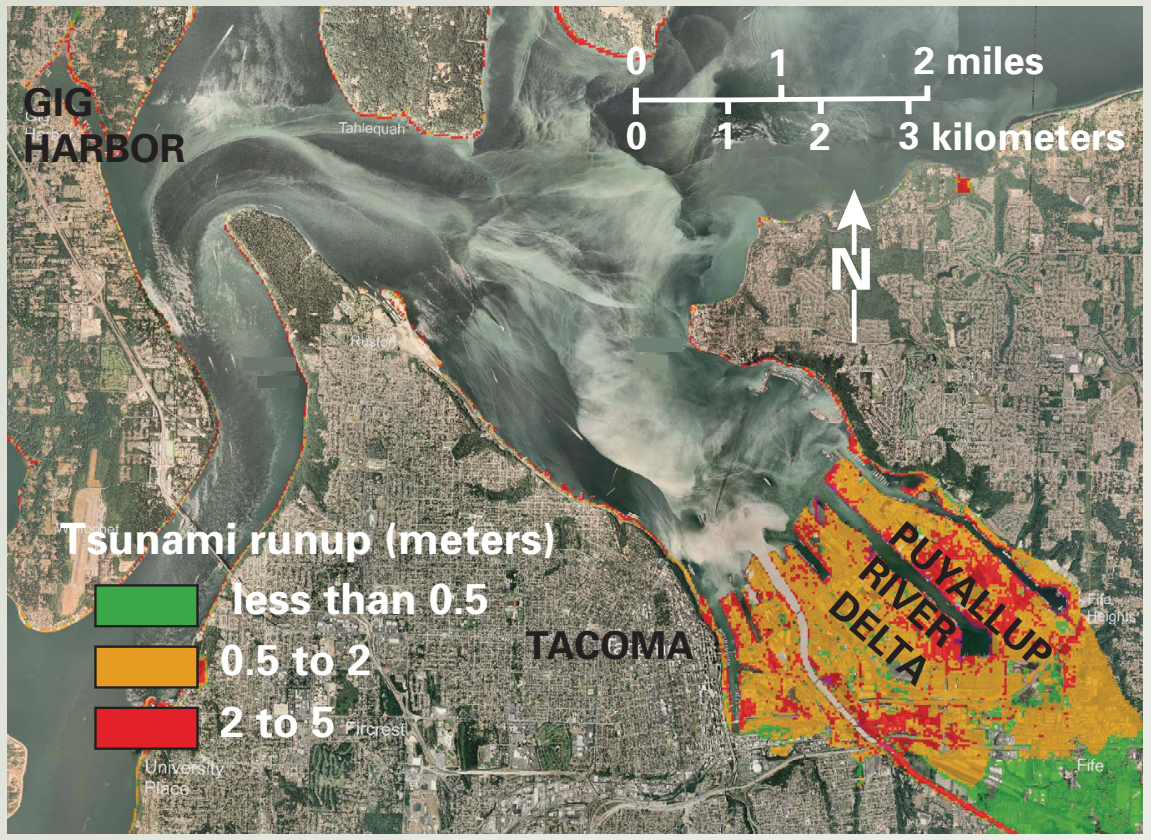

A magnitude 7 earthquake in the Tacoma Fault Zone could offset the floor of Puget Sound and generate a tsunami. Most of the low-lying areas in the Puyallup River delta will likely be subjected to flooding by tsunamis. The maximum tsunami runup for the simulated Tacoma Fault Zone quake shows water reaching an elevation of about 12 feet ( 4 meters), and initial flooding in the Tacoma area would occur about 5 minutes after the earthquake. (Image courtesy of Washington Division of Geology and Earth Resources.)

historical evidence shows that landslides and failures of the sediments in river deltas have generated tsunamis within Puget Sound in the past.

Computer simulations of tsunamigenerating earthquakes show that most of the low-lying areas in the Puyallup River delta are vulnerable to flooding by tsunamis. The maximum tsunami runup for the simulated Tacoma Fault Zone quake shows water reaching an elevation of about 12 feet ( $\sim 4$ meters) and that initial flooding in the Tacoma area would occur about 5 minutes after the earthquake.

Liquefaction - Severe shaking during an earthquake can cause sediments to lose strength. In water-saturated sediments 


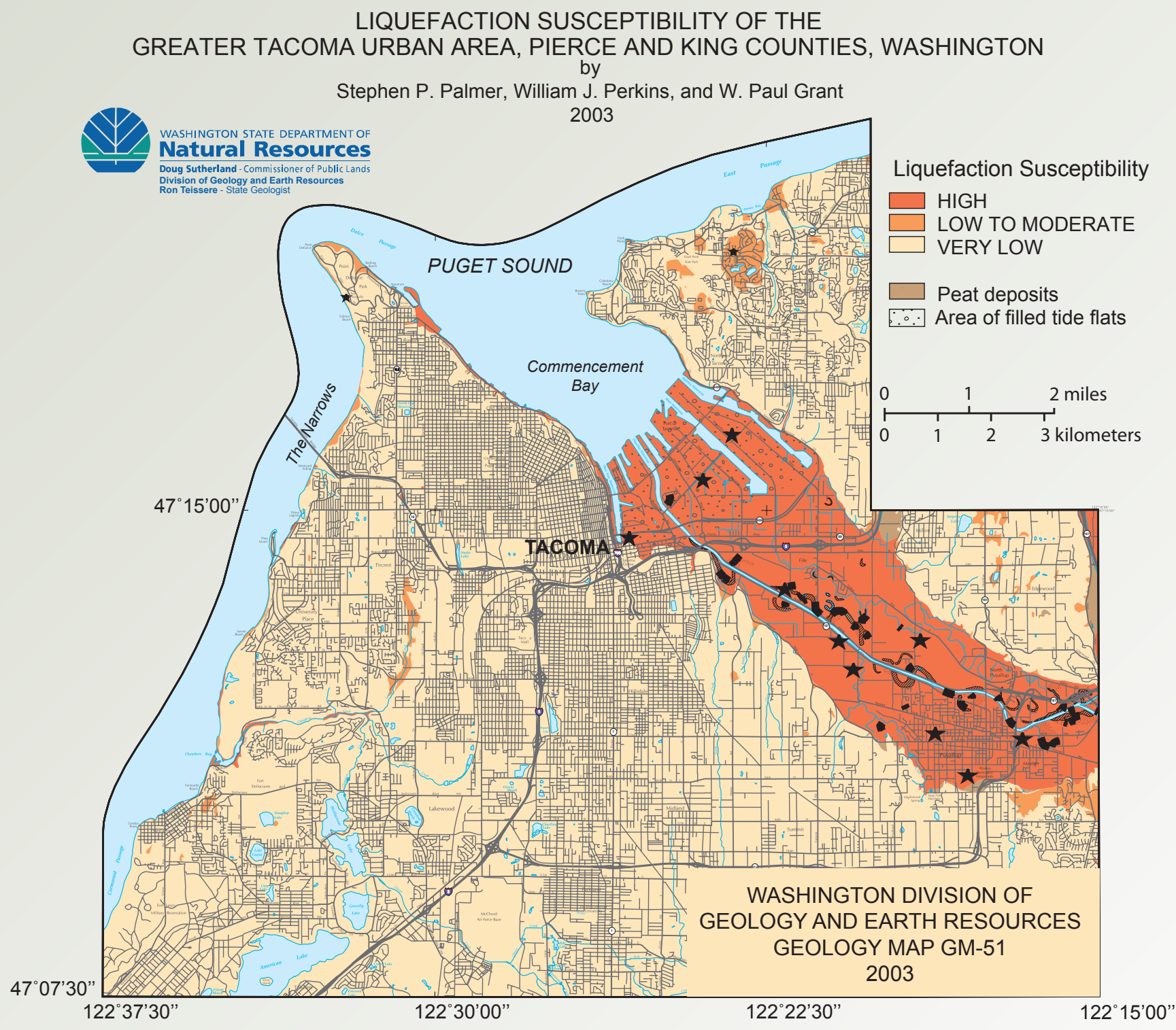

Shaking during earthquakes can cause water-saturated sediments to fail in a process called "liquefaction," resulting in damage to overlying buildings and structures. This map shows liquefaction susceptibility for the greater Tacoma urban area. Some locations are particularly susceptible, such as the abandoned channels (short black meandering lines) of the Puyallup River and Wapato Creek, and have liquefied repeatedly in past earthquakes (stars show sites of past liquefaction). (Image courtesy of Washington Division of Geology and Earth Resources.)

strong shaking during an earthquake can disrupt the grain-to-grain contacts and cause the sediments to compact. When compaction occurs, pressure in water-filled pores (the water between sediment grains) increases, which causes the sediment to lose its strength. This sometimes results in small geyser-like eruptions of water and sediment called "sand blows."
Sediment in this condition is liquefied and behaves as a fluid. Buildings can sink and topple, and foundations can lose strength, causing structural collapse or severe damage. High liquefaction potential exists for areas covered by artificial fill, peat deposits, tidal flats, and stream sediments because they are often poorly consolidated. Some locations, such as the abandoned channels of the Puyallup River and Wapato Creek, are particularly susceptible and have liquefied repeatedly in past earthquakes. Liquefaction failure from the 1949 earthquake killed two people at the Port of Tacoma, despite that quake's much greater depth and less severe shaking than the magnitude 7.1 quake modeled in this scenario. 


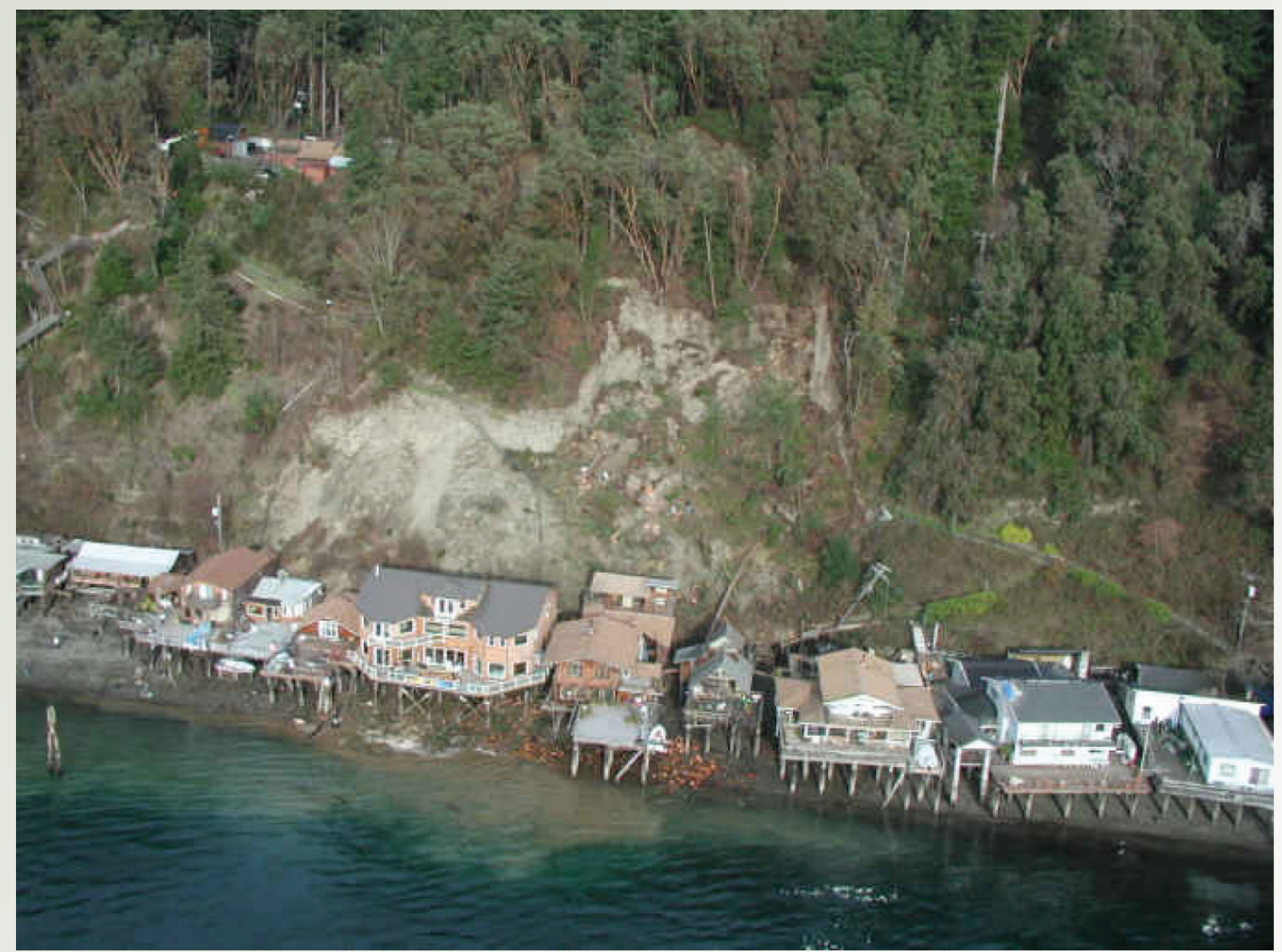

Earthquake shaking may cause landslides on slopes, particularly where the ground is water saturated or has been modified (for example, by having stabilizing vegetation removed). This photograph shows landslides at Salmon Beach, near Tacoma, that were caused by the 2001 magnitude 6.8 Nisqually earthquake, which resulted in an estimated \$2 billion in damage and is one of the largest recorded quakes in Washington's history. Slopes along coastal areas of the southern Puget Sound region are particularly vulnerable to landsliding during powerful earthquakes.

Landslides-Earthquake shaking may cause landslides on slopes, particularly where the ground is water saturated or has been modified (for example, had stabilizing vegetation removed). Steeper slopes are most susceptible, but old, deep-seated landslides may be reactivated, even where gradients are as low as $15 \%$. Catastrophic debris flows can move water-saturated materials rapidly and for long distances, mostly in mountainous regions. Underwater slides also have occurred in the Puyallup River delta in past earthquakes.

Although the magnitude 7.1 earthquake scenario for the Tacoma Fault Zone was modeled using the best scientific information available, it still represents a simplified version of expected ground motions. The damage resulting from ground motions in an actual earthquake of similar magnitude is likely to be even more variable than that modeled, depending on the specific characteristics of each affected structure and its surrounding environment.

The information from this hypothetical but plausible earthquake scenario is being used to help better prepare residents of the southern Puget Sound region for future earthquakes in the Tacoma Fault Zone. The work of USGS scientists in the Puget Sound region is only part of the USGS Earthquake Hazards Program's ongoing efforts to protect people's lives and property from the earthquakes that are an inevitable part of life in the Pacific Northwest.
Joan Gomberg, Brian Sherrod, Craig Weaver, and Art Frankel

Edited by James W. Hendley II Graphic design by Judy Weathers

COOPERATING ORGANIZATIONS

Pacific Northwest Seismic Network, Dept. of Earth and Space Sciences,

University of Washington

Washington Department of Natural Resources

\begin{tabular}{|c|}
\hline For more information contact: \\
Joan Gomberg \\
U.S. Geological Survey \\
University of Washington, \\
Dept. of Earth and Space Sciences, \\
Box 351310, Seattle, WA 98195 \\
gomberg@usgs.gov \\
http://earthquake.usgs.gov/ \\
This fact sheet and any updates to it are avalable \\
on line at \\
http://pubs.usgs.gov/fs/2010/3023/
\end{tabular}

